\title{
Korean Cleft Palate-Craniofacial Association: history and perspectives
}

\author{
Kwang Seog Kim \\ Editor-in-Chief, Archives of Craniofacial Surgery, Department of Plastic and Reconstructive Surgery, Chonnam National University Medical \\ School, Gwangju, Korea
}

The "Korean Society of Plastic and Reconstructive Surgeons (KSPRS)" was founded in 1966, and since then, its members have been actively involved in the development of their respective specialties through both practice and research. On June 19, 1993, members of the KSPRS specializing in head and neck surgery formed a research and study group called "The Korean Association for Cleft Palate and Related Craniofacial Anomalies," with 46 members initially. On December 9, 1995, this group was renamed "The Korean Association for Cleft Palate and Craniofacial Surgery" and became a subsidiary and subspecialty society of the KSPRS. The name of the society was changed again to its current name, "Korean Cleft Palate-Craniofacial Association (KCPCA)," on June 27, 1998 [1]. KCPCA, having grown into a major society with more than 800 full members and 300 associate members currently, celebrates its 26 th anniversary this year. The domain of KCPCA has expanded greatly to cover reconstruction of congenital malformations, treatment of traumas and tumors of the head and neck, as well as cosmetic surgery procedures. Many members therefore are even of the opinion that the name of the society (KCPCA) no longer adequately expresses the full extent of the academic domain of the society. Nevertheless, in a nod to its history, KCP$\mathrm{CA}$ continues to use its traditional name in its current form.

KCPCA is dedicated to contributing to the academic development of its field through a broad range of academic events and to enhancing the competency of young surgeons through vari-

\section{Correspondence: Kwang Seog Kim}

Department of Plastic and Reconstructive Surgery, Chonnam National University

Medical School, 42 Jebong-ro, Dong-gu, Gwangju 61469, Korea

E-mail: pskim@chonnam.ac.kr

Received February 16, 2019 / Accepted February 18, 2019 ous training programs. Every year, KCPCA holds a symposium in spring and an annual meeting in autumn. Starting in 2011, KSPRS' annual meeting is being held as an international congress and English was adopted as the official language in 2016 [2]. Since the annual meeting of KCPCA is traditionally being held concurrently with and at the same location as KSPRS' annual meeting, KCPCA also chose English as the official language for its annual meetings starting in 2016. KCPCA holds workshops twice a year that are aimed at training plastic surgery residents and young specialists in essential head and neck surgery techniques that often do not receive sufficient attention during residency.

KCPCA continually strives to improve its global standing through a policy of active academic exchange and cooperation with overseas societies. Since first being invited by the "European Association for Cranio-Maxillo-Facial Surgery (EACMFS)" as a guest society to its 20th Congress in 2010, KCPCA, in recognition of its academic competence, has been a fixture at this biennial event ever since [3]. Through its cooperation with EACMFS, KCPCA is expanding its international exchange activities to various national societies within EACMFS. Since first participating in the 44th annual meeting of the Egyptian Society of Plastic and Reconstructive Surgeons (ESPRS) as a guest society in 2014, KCPCA and ESPRS have continued a tradition of inviting speakers to each other's annual meetings [2]. Through this cooperation with ESPRS, KCPCA hopes to be able to establish relationships with societies in other African and Middle Eastern countries. KCPCA's policy is to actively pursue official cooperative relationships with national societies throughout the world in order to encourage contacts between people and ex- 
change of information as a means to contribute to global development.

The KCPCA began publishing an official journal in October 2000, under the title of Journal of the Korean Cleft Palate-Craniofacial Association (J Korean Cleft Palate Craniofac Assoc; JKCPCA). It was published in Korean twice a year from 2000 to 2011. In 2012, its title was changed to Archives of Craniofacial Surgery (Arch Craniofac Surg; ACFS). ACFS was published in Korean twice a year between 2012 and 2013. In 2014, the official journal language was changed to English. ACFS' publication frequency increased to three times a year in 2014 and 2015, and to four times a year between 2016 and 2018. From 2019 on ACFS will be published bimonthly. With inclusion of ACFS in PubMed Central, biomedical scientists from all over the world have access to the journal's contents. This resulted in an increase in citations of articles published in ACFS and also in an increase in submitted papers to the journal. With the forthcoming listing of ACFS in Scopus in 2019, searching journal articles will become even easier than before.

KCPCA has grown rapidly as a society not only in terms of scale and scope, but also in terms of academic excellence and reputation over a relatively short period of time. However, KCPCA faces the continuing challenge to actively respond to ever-changing demands in the areas of diseases and treatments thereof, to mitigate damage caused by less-than-sufficiently qualified practitioners from other medical fields, to educate the public and to promote a wider understanding of KCPCA's domain of expertise. In view of the inevitable and accelerating trend of globalization of all areas of science due to the rapid development of information and communication technologies, KCPCA too must strive to achieve and maintain academic ex- cellence and competitiveness in a global context. Therefore, KCPCA endeavors to foster and encourage harmony among and participation by members, to develop and organize a variety of types of academic conferences and events to meet its members' needs, to develop systems and infrastructure aimed at continuously improving the healthcare environment for doctor's medical practice, and to promote active exchange with overseas societies.

\section{NOTES}

\section{Conflict of interest}

No potential conflict of interest relevant to this article was reported.

\section{OCID}

Kwang Seog Kim https://orcid.org/0000-0002-6766-4640

\section{REFERENCES}

1. Korean Cleft Palate-Craniofacial Association. About us [Internet]. Seoul: Korean Cleft Palate-Craniofacial Association; c2005 [cited 2019 Jan 1]. Available from: http://www.kcpca. or.kr/.

2. Lew DH. PRS KOREA 2016: 50th anniversary of the Korean Society of Plastic and Reconstructive Surgeons and another successful congress for plastic and reconstructive surgery. Arch Plast Surg 2017;44:1-2.

3. Lee Y. Spring update: a letter from the president of the Korean Cleft Palate-Craniofacial Association. Arch Craniofac Surg 2016; 17:43. 